\title{
Lurking, anonymity and participation in computer conferencing
}

\author{
John Pearson \\ Monash University, Churchill, Victoria 3842, Australia. \\ iohn.pearson@education.monash.edu.au
}

Keywords: computer-mediated communication, electronic networking, pre-service teacher education, computer conferencing

\begin{abstract}
This paper presents data from a case study on the use of electronic networking in an initial teacher education course. These data revealed that the network was used extensively for private mail but only to a limited extent for public conferencing except for one conference where trainee teachers were able to use an anonymous account when contributing messages. The reasons for limited participation by trainee teachers in conferences, and the ways in which access to an anonymous account influenced participation on the network, are discussed drawing on interview data from trainee teachers.
\end{abstract}

\section{INTRODUCTION}

This paper present data from a case study on the use of electronic networking in the fourth year of an initial teacher education course. A feature of the course was a 'school-based' practicum, developed in partnership with local schools, and one of the innovative features was the provision of an electronic network for individual mail and computer conferencing amongst trainee teachers, classroom teachers and university staff. Data on the nature and extent of usage by trainee teachers are presented. These data revealed that the network was used extensively for private mail but only to a limited extent for public conferencing, except for one conference, Course Comments, containing evaluative comments about the course, where trainee teachers were able to use an anonymous account

\footnotetext{
The original version of this chapter was revised: The copyright line was incorrect. This has been
} corrected. The Erratum to this chapter is available at DOI: 10.1007/978-0-387-35499-6_29 
Mary Smith when contributing messages. The reasons for limited participation by trainee teachers in all conferences, except Course Comments, are discussed, drawing on interview data collected at the end of the course.

\section{THE SCHOOL-BASED COURSE}

The 'school-based' course aimed to engage trainee teachers in:

- co-operative planning, teaching and reflective practice;

- maintaining a reflective journal;

- teaching regularly across curriculum areas;

- attending and presenting at curriculum committees and seminars;

- interacting with the wider school community;

- seminars with school staff and liaison lecturers;

- a 6,000 word report on a topic;

- computer conferencing with other participants;

- compiling a professional employment portfolio.

(Standards Council of the Teaching Profession 1995)

The course was premised on notions of 'collegiate relationships' between participants, 'negotiated curriculum' in terms of activities in schools, and 'research about practice' (problem-solving, evaluations) (Cairns et al, 1995). Trainee teachers $(n=26)$ maintained regular contact with one primary school throughout the year. Part time 'liaison lecturers' provided guidance and support to trainee teachers and classroom teachers. Since schools had no useful hardware, the university provided computers, modems, printers and telephone connections in each school, installed the communications software (First Class), and provided training in its use for all participants. No requirements about the nature and extent of usage of the network were imposed on participants.

\section{NETWORK USE BY TRAINEE TEACHERS}

Figure 1 shows the nature and extent of network use by trainee teachers. Trainee teachers accounted for $85 \%(n=1256)$ of loggias to the network, $82 \%(n=721)$ of private messages created, and $68 \%(n=130)$ of messages placed in conferences. Figure 1 reveals that trainee teachers used the network extensively for private messages but only to a limited extent for conferencing. 


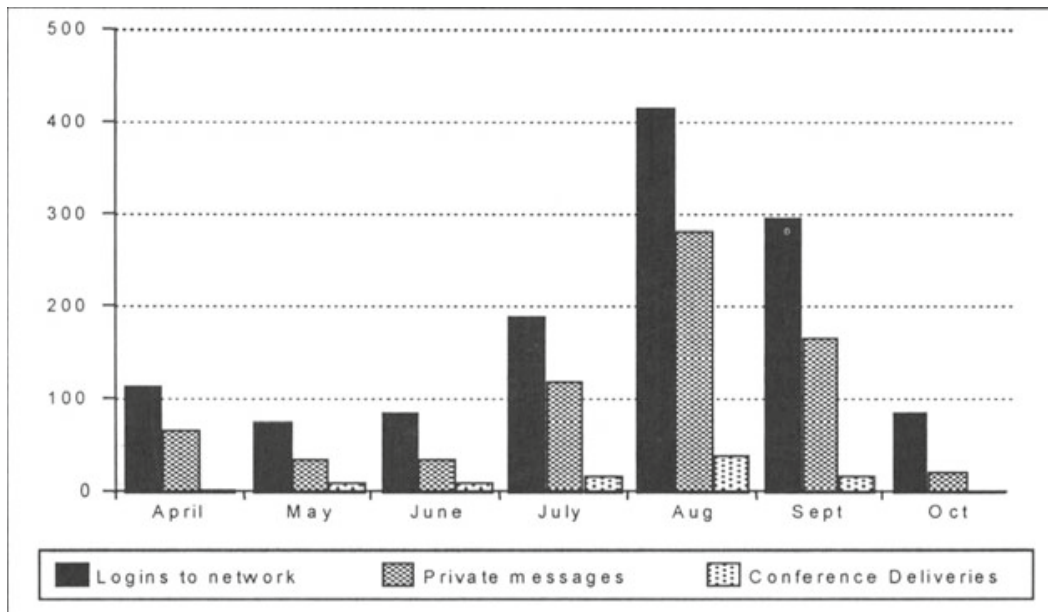

Figure 1. Network use by trainee teachers

Data from questionnaires revealed that few difficulties were experienced using the First Class communications software, which was considered to be 'easy' (90\%) and 'fun' (77\%) to use. Only 14\% thought they were at a 'basic level' when using the software, the remaining $86 \%$ considered they were at 'higher' or 'advanced' levels. Strongly positive responses were received about the value of the network; electronic communication was considered to be very useful for 'receiving information' (91\%), 'social contacts' $(95 \%)$, 'teaching projects' ( $86 \%)$, 'discussing educational ideas' $(81 \%)$, 'dealing with personal and professional problems' $(71 \%)$ and 'developing a sense of community' amongst participants (81\%).

These are interesting and useful findings, indicating that there is scope to incorporate electronic networking in initial teacher education courses and that trainee teachers consider that there are benefits in doing so. However, a more detailed examination of the messages contributed to conferences indicates that only three conferences - Stafford (67 messages), Course Comments (57 messages) and Projects (36 messages) - had relatively high message counts. Other conferences $(n=11)$, set up at the request of trainee teachers to discuss curriculum issues, were poorly supported (0-15 messages). Conferences other than Course Comments were noticeboards, with messages publicising forthcoming meetings or social events, rather than forums for comments about teaching practices, curriculum issues or educational ideas. To investigate why this occurred, interviews were completed with trainee teachers $(n=21)$ at the end of the year. 
4. FACTORS INFLUENCING PARTICIPATION BY TRAINEE
TEACHERS

While concerns about features of the 'school-based' programme (such as workload and assessment) impacted on participation on the network at various times, the focus here is on concerns directly related to the use of the electronic network for discussion purposes.

\subsection{The public nature of communication}

'Negotiating' a relationship with the electronic network and, in particular, the conferencing facility proved to be a particularly difficult task for many trainee teachers (TTs). They found that nothing in their teacher education course had prepared them to put forward ideas in the 'public' way required in conferencing. In previous years, they had been passive listeners rather than active contributors in university classes.

Looking back over the three years you could count on your fingers the number of times you actually had to get up in front of everybody and do something. And then you're stuck on this thing where everything you do is in front of everyone else. So it's a big change. [TT12]

It might also be anticipated that teaching practice in previous years may have developed confidence about public presentations. However, trainee teachers were unable to transfer the skills and confidence gained during face-to-face interaction (with children, as well as adults) to the electronic medium.

Teaching children isn't as intimidating as presenting your own ideas to people your own age or older. Even though you might be quite confident in front of 30 or so kids, when it comes to actually participating in conversations relating to class work or whatever it's just dramatically different. [TT13]

\subsection{Envisaging the audience}

Another problem for trainee teachers thinking about contributions to conferences was envisaging the audience. In assignments in other subjects, trainee teachers had written what they perceived the lecturer wanted:

In most of our Uni life we've gotten to know the lecturers in the classes

we've been in and you'll tend to write what you think the lecturer wants 
from you. You know what particular lecturers look for. I don't think you necessarily write the same way for all lecturers. [TT13]

However, on the network they were uncertain about how to compose messages which would be read by an audience which comprised other trainee teachers, classroom teachers and university staff.

You're thinking: 'Who am I actually writing to? How do I write this?' You've got a whole range of people reading what I'm writing [on the network]. You've got lecturers, other teachers. You've got fellow students. What sort of stuff do I put in it? [TT13]

The content of messages was not the only problem. Without previous experience of 'network genre', trainee teachers were uncertain about how to write.

I've got to write in a non-relaxed form for me when I'm on the network. I feel like I've got to write in a formal way and that puts me off. [TT3]

The difficulty of making decisions about writing 'style' is also reflected in the following passage from another trainee teacher.

You have to adjust to it. You can't just write exactly what you mean when you're typing it. You have to really explain yourself a lot. When you're having a chat with someone they can fill in the gaps really easily. [TT5]

'Time' was another problem. In some cases, this referred to the competing demands of other components of the 'school-based' programme, but in other cases the concern with 'time' related to 'reflective writing'.

It takes me a long time to think about what I'm going to write and edit it. I edit and edit all the time to try and make the point that I want to make so that its not ambiguous. So, I'm constantly editing and that's time consuming. And sometimes I've felt under pressure with time on the network and I've sent something and thought afterwards that I could have done better. [TT20]

\subsection{Cues}

Another difficulty for some trainee teachers was the loss of visual and verbal cues associated with face-to-face conversations when communication was mediated via an electronic network. 
It's hard typing something on the computer because, when you are talking to someone, you know with the tone what they're meaning. If they're being sarcastic you know, but on the computer you don't. [TT1]

Another trainee teacher made the following comments:

If you're there you can read what a person's body language says and you can see if they're understanding what you mean and you can communicate more effectively face-to-face or over the telephone because you can listen to what they're saying in response to what you're saying and you can modify your message so that they understand what you mean. [TT16]

In the 'school-based' programme, the electronic network had been introduced to facilitate communication between course participants. But for trainee teachers, computer-mediated communication was about writing, since active participation in computer conferencing involved composing written messages. Their fundamental concern was the written nature of communication, evident in the language they used in interviews when talking about the network; sending messages was described as 'writing on the computer'; messages were referred to as 'letters'; and replies involved 'writing back'. Only a few trainee teachers talked about the network as a place to share ideas, to become familiar with other points of view or to justify their own ideas about concepts and issues to do with teaching.

\subsection{Criticism}

Since computer conferencing was about writing, rather than communication, it is not surprising that the major concern of trainee teachers - mentioned in almost every interview - was fear of criticism from others about what they had written. An incident early in the year reinforced their worst fears.

It was a response to one project outline (contributed by a trainee teacher) which heightened anxiety about the vulnerability of written communication. This response, by a university staff member (US), was designed to foster discussion and provide helpful information, but this was not the way it was perceived by the trainee teacher who had proposed the project. According to another university staff member:

[She came] tearing into my office after school one day saying, "Who is this?', and she used a very short word for him. And then she gave me a half hour diatribe on why she thought he had no right to have any opinion on what she did. And she was deeply offended. There was no 
idea of the contribution of a colleague or why he wrote it. It just offended her utterly. [US2]

The same university staff member made another contribution a few days later clarifying the meaning of 'hypothesis' and the way a hypothesis was framed. Again, the message was designed to assist trainee teachers to design their projects in schools, but the 'academic' language used was construed as intimidating. Not surprisingly, trainee teachers decided to avoid written contributions to conferences which could expose their own inadequacies. As one trainee teacher commented: Better to remain silent and be thought a fool than to open your mouth and remove all doubt. [TT10]

These comments by trainee teachers reveal some of the problems they experienced negotiating the conferencing facility on the network. The fear of criticism about what they wrote was a particular problem which most failed to resolve. Hence, public messages addressed to conferences usually took the form of notices about professional development courses or social activities, 'safe' because these messages simply conveyed information and nothing about their own views which might be open to 'criticism'.

\section{PARTICIPATING ANONYMOUSLY - THE MARY SMITH ACCOUNT}

The suggestion for a Course Comments conference, and an anonymous account which could be used to contribute messages, arose at a campus meeting three months after the 'school based' course commenced. Course Comments (often called the Mary Smith conference) was the most successful of the conferences on the network - message counts were relatively high $(n=57)$, and message content revealed a high level of interaction (comments on issues raised in other messages) amongst participants.

The Mary Smith account enabled many trainee teachers to handle problems associated with using their own accounts. As anonymous participants, it did not matter what, or how they wrote. One trainee teacher, who had made no contributions to conferences except Course Comments using the anonymous account, considered that:

It wasn't personalised. No-one knew who it was so they couldn't attach a name to it. So the criticism wasn't taken to heart. [TT12] 
Another trainee teacher thought that the anonymous account was a good idea because:

You don't feel so bad about coming back as Mary Smith and giving feedback. It's not friends or people you know. You don't want to step on peoples' toes. You can actually give feedback whether its critical or positive. [TT18]

Mary Smith was also a way to contribute ideas with 'no strings attached':

I wrote it under Mary Smith because I couldn't be bothered getting back all the garbage that would come if I wrote it under my own name. I' $d$ be getting personal comments back to my [mail]box and on to me personally and I didn't want that. [TT14]

\section{ANONYMITY AND NETWORK PARTICIPATION}

The use of an anonymous account was an interesting innovation which is perceived to have increased participation in one conference. In view of this outcome, the literature was reviewed to locate previous research which might present insights about anonymity and network participation.

Some electronic networks have provided opportunities for participants to use pseudonyms, although the justification for this decision, and an explanation for its effects, has not always been provided (Kimmel et al, 1988). In another reported application in a first year elementary teacher education course, the instructor in the course did not participate in discussions and all students did so anonymously 'to encourage nondominated dialogue' (Harrington and Quinn-Leering, 1995). However, the impact of these decisions on participation was not discussed.

Two case studies located in the literature did provide some justifications for decisions taken and effects observed. At San Diego State University, computer conferencing was used to supplement face-to-face lectures and class discussions in one subject. The 'majority' of students in the class were 'adult Hispanic women' who were reported to have become 'very assertive' by the end of the course. In this case, the use of 'pen names' was considered to be important in initiating discussion, but not necessarily in sustaining it:

When students met in class, they did not engage in heated debate, nor was any attempt made to criticise the ideas and comments of anyone in the class. Although the class began with no one knowing anyone else's identity, the students soon began to share their pen names with friends. Within the first two weeks, either through direct revelation or second-hand gossip, all 
identities became known. Consequently, the use of anonymous identities was a valuable pedagogical resource for initiating the discussion, but it was the anonymity provided by the medium that sustained it and promoted the strong assertive remarks (Bellman 1992:60).

The 'anonymity provided by the medium' was not fully explained but presumably referred to network discussions in which 'women are able to express themselves much more easily and fully without being interrupted or ignored' (Bellman 1992) by other (male?) participants. If the 'characteristics of the medium' sustain discussion, anonymity may only be important in the initial stages of network interaction.

The impact of anonymity in the initial stages of network use has also been identified in a case study of the TeleNex (Hong Kong) network for non-native speaking English teachers. After four months, teachers reported that it was 'very threatening to have their names appearing in the messages, and even more threatening to have their school names appearing as well' (Tsui 1995). These teachers were concerned about perceptions of their personal competence with English, their knowledge about teaching English as a second language and, as a result, the reputation of their schools which might be held by others.

Modifications were made to the software so that public messages to conferences could be:

anonymous, using personal name only, using school name alone, or using both... Subsequently, it was felt that signing off a message as anonymous has an undesirable effect on secrecy and this option was changed to 'An English Teacher'. (Tsui 1995)

Data on usage patterns with these options were not presented but Tsui (1995) noted that:

The implementation of this modification ['An English Teacher'] for two months shows that most new users preferred to use 'An English Teacher' whereas the old users, especially panel chairs, used the default option of having their personal and school names appearing.

Hence, it would appear that 'pen names' may be useful in the initial stages of network use. As participants develop confidence in writing messages, and gain familiarity with the ways other users respond to messages, the use of actual names may be generally adopted. 


\section{CONCLUDING COMMENTS}

Lurking occurs frequently in electronic discussions, but the reasons for this phenomenon have not been widely researched. The findings presented from this case study involving trainee teachers revealed special reasons for this behaviour, which may help to focus further research on the difficulties experienced by some users. The impact of an anonymous account on the participation by trainee teachers has also been outlined, but the opportunity to fully investigate the effects of network participation and message contributions was not realised by the author while the research was in progress. However, the effects observed with novice users of communications software in this case study, and the available reports of other evaluations of electronic networking, would appear to indicate that anonymity may increase participation particularly in the early stages of network use. The benefits of asynchronous communication (equal opportunities to participate, no interruptions by assertive members) cannot always be realised when users lack confidence in using the medium as the trainee teachers in this case study demonstrated. Further research on the effects of anonymity on network participation might result in earlier and more confident participation by novice users without the need to resort to sanctions (such as specifying the nature and extent of contributions) as is often the case.

\section{REFERENCES}

Bellman, B. L. (1992) Computer communications and learning. New Directions for Teaching and Learning 51, 55-63.

Cairns, L., Southcott, J., Osborn, M., and Clingan, R. (1995). The Monash primary schoolbased teacher education programme. Paper presented at the 25th Annual Conference of the Australian Teacher Education Association, Sydney. [URL: ftp://info.mq.edu.au/pub/edu/ lcairns.doc]

Harrington, H. L. and Quinn-Leering, K. (1995) Fostering moral discourse with technology. Paper presented at the Annual Meeting of the American Educational Research Association under the title 'Using technology to prepare effective and responsible educators'. San Francisco, April.

Kimmel, H., Kerr, E. B., and O'Shea, M. (1988). Computer conferencing as a resource for inservice teacher education. Science Education, 72 (4) 467-473.

Standards Council of the Teaching Profession (SCTP) (1995) Partnerships in teacher education. Melbourne: SCTP.

Tsui, A. B. M. (1995) Social factors in the implementation of a computer network for English language teachers. Journal of Information Technology for Teacher Education. 4 (2) 149164. 


\section{BIOGRAPHY}

John Pearson is Senior Lecturer in the Faculty of Education, Monash University, Victoria, Australia. He has taught for many years in initial and continuing teacher education courses. His current research interests focus on the ways in which communities of practice can be fostered through the use of computer conferencing in professional education and training. 